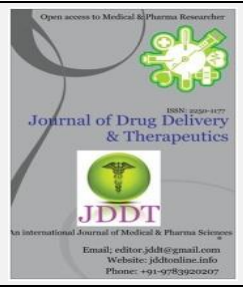

Open $\odot$ Access

Research Article

\title{
Formulation and evaluation of Zidovudine alginate microspheres
}

\author{
Pingali Srinivasa Rao*, Kanakam Vijayabhaskar \\ St.Peter's Institute of Pharmaceutical Sciences, Vidyanagar,Hanamkonda,Warangal Urban,T.S-506001
}

\begin{abstract}
The objective of the present study was to prepare and evaluate microspheres for the controlled release of Zidovudine from the prepared microspheres using different polymers. The microspheres were prepared by ionic gelation method. The prepared microspheres were characterized for FTIR, scanning electron microscopy (SEM), the percentage drug content, entrapment efficiency, and in vitro dissolution studies. Accelerated stability studies were also carried out for the formulations. The microspheres were spherical in shape and free flowing. The entrapment efficiency was varying from 76 to $86 \%$. The release of drug from the microspheres was extended up to 8 to 12 hours. FTIR studies showed the stable character of Zidovudine in the microspheres. SEM studies revealed that the microspheres were porous in nature. The release kinetics studies revealed that the prepared microspheres were best fitted to the zero order for all eight formulations and peppa's model. The release kinetics data and characterization studies indicated that the drug release from microspheres was diffusion - controlled and the microspheres were stable in nature.
\end{abstract}

Keywords: Zidovudine, microspheres, controlled release, stability, ionic gelation, entrapment efficiency.

Article Info: Received 22 July 2019; $\quad$ Review Completed 17 Aug 2019; Accepted 25 Aug 2019; Available online 15 Oct 2019

Rao PS, Vijayabhaskar K, Formulation and evaluation of Zidovudine alginate microspheres, Journal of Drug Delivery and Therapeutics. 2019; 9(5-s):57-64 http://dx.doi.org/10.22270/jddt.v9i5-s.3607

*Address for Correspondence:

Pingali Srinivasa Rao, St.Peter's Institute of Pharmaceutical Sciences, Vidyanagar,Hanamkonda,Warangal Urban,T.S506001

\section{INTRODUCTION}

Acquired Immunodeficiency Syndrome (AIDS), which is now a plague in several countries, was first identified in California in 1981. According to data published in the December, 2003 AIDS Epidemic Update, [1] an estimated 40 million people were living with HIV/AIDS at the end of 2003, of whom as many as $70 \%$ are living in Sub-Saharan Africa. In addition, an estimated 3 million people died of HIV/AIDS during 2003, of whom as many as $80 \%$ were living in sub- Saharan Africa. The World Health Organization (WHO) estimates that HIV/AIDS caused $2 \%$ of all deaths and $6 \%$ of deaths due to infectious diseases in India in 1998. If current HIV/ AIDS policies continue, by 2033 AIDS will account for an estimated 17 percent of all deaths and 40 percent of deaths from infectious disease. Following the launch of generic antiretroviral drugs by Indian pharmaceutical companies in 2000 and the decline in the costs of these drugs, an increasing number of people with HIV/AIDS have been using antiretroviral therapy. Of the estimated 550,000 people with AIDS in India, 370,000 reside in 60 major cities. Physicians in these cities are treating 90,000 of these people, 11,700 of whom $(8,700$ males and 3,000 females $)$ are receiving antiretroviral therapy [2]. In such a way the antiretroviral therapy play essential role in the management of AIDS patients.

Zidovudine is a synthetic nucleoside analog that is being increasingly used as the core of an antiretroviral regimen for the treatment of HIV infection. Zidovudine, the (-)enantiomer of $2^{\prime}, 3^{\prime}$-dideoxy-3'-thiacytidine, is a nucleoside analog that inhibits HIV reverse transcriptase. [3] In vivo, nucleoside analogs are phosphorylated intracellularly by endogenous kinases to putatively active $5^{\prime}$ - triphosphate (3TC-TP) derivatives that prevent HIV replication by competitively inhibiting viral reverse transcriptase and terminating pro viral DNA chain extension. [4,5] Zidovudine is rapidly absorbed after oral administration with an absolute bioavailability of $86 \% \pm 16 \%$, peak serum concentration of Zidovudine (Cmax) of $1.5 \pm 0.5 \mathrm{mcg} / \mathrm{mL}$ and mean elimination half-life ( $\left.t \frac{1}{2}\right)$ of 5 to 7 hours, thus necessitating frequent administration to maintain constant therapeutic drug levels. [6]Therefore, the objective of the present work is paying attention to provide a long acting pharmaceutical formulation containing Zidovudine in a modified release matrix as microspheres, to maintain the blood levels of the active ingredient for a prolonged period of time [7].

\section{MATERIALS AND METHODS}

\section{Materials}

Zidovudine was obtained as a gift sample from Milton Labs, Pondicherry. HPMC, Chitosan, Sodium Carboxyl methyl cellulose was Gift sample from novel drugs, Trichy. Sodium Alginate, Calcium Chloride, bought from S.D Fine chemicals, 
Mumbai. All the chemicals and reagents used in the study were of analytical grade.

\section{Preparation of microspheres}

The microspheres were prepared by the ionotropic gelation technique. The sodium alginate solution was prepared by dispersing the sodium alginate in de-ionized water under continuous stirring for 30 minutes. The weighed amount of the drug was thoroughly mixed with sodium alginate dispersion. By following the same procedure the alginate beads of different ratios of drug: polymer were prepared. The resulted homogeneous dispersion was extruded in to the $5 \%$ calcium chloride solution through hypodermic syringe with flat tip needle (20G) and stirred for 15 minutes at $100 \mathrm{rpm}$ using magnetic stirrer. The formed micro beads were allowed to cure for 30 minutes in the calcium chloride solution to complete the gelation reaction. The microspheres were then filtered and dried in hot air oven at $60^{\circ} \mathrm{C}$ for $3 \mathrm{hr}[8,9,16,18,19]$.

\section{CHARACTERIZATION OF MICROSPHERES}

\section{FTIR study}

The Zidovudine microspheres were subjected to FT-IR analysis by the following method [23], an approximately minimum quantity (less than $4 \mathrm{mg}$ ) of sample was thoroughly blended with adequate quantity of IR grade $\mathrm{KBr}$ (less than $100 \mathrm{mg}$ ) in mortar. The mix was then made into $\mathrm{KBr}$ pellets by hydraulic compression lever. The samples were the analyzed in a double beam IR spectrometer using $\mathrm{KBr}$ film as negative control (blank).

\section{Scanning electron microscopy}

Morphological details of the specimens were determined by using a scanning electron microscope (SEM).

\section{Granulometric studies}

Particle size distribution pattern was determined by sieve analysis on mechanical sieve shaker $[16,20]$, using different meshes $(12,16,20$ and 30) of American society of testing materials.

\section{Micrometric properties of the beads}

The mean particle size of the alginate microspheres was determined by optical microscopic method using a precalibrated stage micrometer [10].

\section{Flow properties of Beads}

The flow properties of prepared microspheres were investigated by measuring the Angle of Repose by using fixed funnel method [17]. Depends upon these values, the flow properties of the microspheres can be assumed. The Angle of Repose Values was mentioned in the Table-3. The value of angle of repose was calculated by using the following formula,

$$
\text { Angle of repose }(\theta)=\tan -1 \mathrm{~h} / \mathrm{r}
$$

$\mathrm{h}=$ cone height, $\mathrm{r}=$ radius of circular base formed by the microspheres on the ground. The bulk and tapped densities were measured in a $10 \mathrm{ml}$ graduated cylinder as a measure of packability of the microspheres. Each experiment was carried out in triplicate. Results were shown in Table-3

\section{Drug content (mg)}

$100 \mathrm{mg}$ microspheres were powdered and transferred into a $100 \mathrm{ml}$ volumetric flask and the volume was made upto the mark with $6.8 \mathrm{pH}$ phosphate buffer and kept aside for $12 \mathrm{hrs}$ with occasional shaking. Then the absorbance was analyzed spectrophotometrically at $270 \mathrm{~nm}$. Three determinations were carried out for each formulation. The drug content was calculated by using the formula;

Drug content $=$ concentration $\times$ dil factor $\times$ conversion factor $x$ amt. of stock sol.

\section{Drug entrapment efficiency}

Zidovudine content in the microspheres was estimated by a UV-spectrophotometric method [10, 11]. Accurately weighed $100 \mathrm{mg}$ of microspheres $(100 \mathrm{mg})$ were powdered and suspended in $6.8 \mathrm{pH}$ phosphate buffer. The resulting solution was kept for $24 \mathrm{hrs}$. Next day it was stirred for $20 \mathrm{~min}$ using ultra sonicator. The solution was filtered through a $0.45 \mu \mathrm{m}$ membrane filter, after suitable dilution, Zidovudine content in the filtrate was analysed at $270 \mathrm{~nm}$ using UV-Visible spectrophotometer. The obtained absorbance was plotted on the standard curve to get the exact concentration of the entrapped drug. Calculating this concentration with dilution factor the percentage of actual drug encapsulated in microspheres was calculated. The drug entrapment efficiency was determined using following relationship

The yield was calculated.

$$
\begin{gathered}
\text { Actual drug content } \\
\text { Percentage yield }=-\frac{\text { Theoretical drug content }}{\text { Then }}
\end{gathered}
$$

\section{In Vitro Drug Release Studies}

In vitro dissolution studies were performed by using USP type I dissolution apparatus at $75 \mathrm{rpm}$ [7]. The microspheres were weighed and filled in the empty capsule shells and placed in the basket. The dissolution medium $(900 \mathrm{ml})$ consisted of $0.1 \mathrm{M}$ hydrochloric acid for the first 2 hours and then changed to phosphate buffer $\mathrm{pH} 7.4$ from 2nd to 10th hour. The temperature was maintained at $37^{\circ} \mathrm{C} \pm 5^{\circ} \mathrm{C}$. An aliquot $(5 \mathrm{~mL})$ was withdrawn at specific time intervals and replenished with an equivalent volume of dissolution fluid. Drug content was determined by UV- visible spectrophotometer at $270 \mathrm{~nm}$.

\section{Kinetics of drug release}

The suitability of several equations to identify the mechanisms for the release of drug was tested with respect to the release data, and it was found that up to $50 \%$ of drug was released. The drug release data of the in-vitro dissolution study was analyzed with various kinetic equations like zero-order [12] ( $\%$ release v/s time), firstorder [13] (Log \% retained v/s time), Higuchi model

[14] and korsmeyer and peppas equation [15]. Coefficient of correlation ( $r$ ) values were calculated for the linear curves obtained by regression analysis of the above plots.

The value of ' $n$ ' gives an indication of the release mechanism; when $\mathrm{n}=1$, the release rate is independent of time (zeroorder) (case II transport), $\mathrm{n}=0.5$ for Fickian diffusion and when $0.5<\mathrm{n}<1.0$, diffusion and non-Fickian transport are implicated. Lastly, when $n>1.0$ super case II transport is apparent. $K$ values are release rate constants according to the models considered; $R^{2}$ values are determination Coefficients; and $n$ is the exponent of the korsmeyer-peppas model.

\section{Determination of stability of the microspheres}

The microspheres prepared in the present study were filled in the hard gelatin capsules and stored in HDPE containers at $40^{\circ} \mathrm{C} / 75 \% \mathrm{RH}$ for 3 months as per ICH guidelines [22]. The samples were then characterized for $\%$ drug content. 


\section{RESULTS AND DISCUSSION}

Preparation of microspheres

Microspheres of Zidovudine were prepared (eight formulations) by ionotropic gelation technique and the formulations were evaluated for different parameters. The compositions of the alginate micro beads were given in the Table-1.

TABLE-1: The compositions of the alginate micro beads

\begin{tabular}{|c|c|c|c|c|c|c|}
\hline nulation code & $\begin{array}{c}\text { Sodium } \\
\text { alginate } \\
(w / v)\end{array}$ & $\begin{array}{c}\text { Calcium } \\
\text { chloride } \\
(w / v)\end{array}$ & $\begin{array}{l}\text { nitosan } \\
(w / v)\end{array}$ & $\begin{array}{c}\text { Sodium carboxy methyl } \\
\text { cellulose } \\
(w / v)\end{array}$ & $\begin{array}{l}\text { HPMC } \\
(w / v)\end{array}$ & $\begin{array}{c}\text { Drug } \\
\text { (Zidovudine) } \\
(w / v)\end{array}$ \\
\hline F1 & $3 \%$ & $5 \%$ & - & - & - & $1 \%$ \\
\hline F2 & $4 \%$ & $5 \%$ & - & - & - & $1 \%$ \\
\hline F3 & $3 \%$ & $5 \%$ & - & $0.5 \%$ & - & $1 \%$ \\
\hline F4 & $3 \%$ & $6 \%$ & - & $1 \%$ & - & $1 \%$ \\
\hline F5 & $3 \%$ & $5 \%$ & - & - & $0.5 \%$ & $1 \%$ \\
\hline F6 & $3 \%$ & $6 \%$ & - & - & $1 \%$ & $1 \%$ \\
\hline F7 & $3 \%$ & $5 \%$ & $0.5 \%$ & - & - & $1 \%$ \\
\hline F8 & $3 \%$ & $6 \%$ & $1 \%$ & - & - & $1 \%$ \\
\hline
\end{tabular}

\section{Characterization of microspheres}

\section{Granulometric studies}

In the granulometric study, it was observed from the table that about 65 - 81 percent of microspheres were of 16 mesh size, which proves the flexibility of the method. The size distribution of microparticles was reported in Table- 2 .

Table - 2: Granulometric Study

\begin{tabular}{|c|r|l|c|r|}
\hline Formulation code & $\begin{array}{c}\# \mathbf{1 2}(\mathbf{1 . 6 8} \mathbf{~ m m}) \\
\mathbf{1 1 9 0 - 1 6 8 0} \boldsymbol{\mu m}\end{array}$ & $\begin{array}{l}\mathbf{1 6}(\mathbf{1 . 1 9} \mathbf{~ m m}) \\
\mathbf{8 4 0 - 1 1 9 0} \boldsymbol{\mu m}\end{array}$ & $\begin{array}{c}\# \mathbf{2 0}(\mathbf{0 . 8 4} \mathbf{~ m m}) \\
\mathbf{5 9 0 - 8 4 0} \mathbf{~} \mathbf{m}\end{array}$ & $\begin{array}{c}\# \mathbf{3 0}(\mathbf{0 . 5 9} \mathbf{~ m m}) \\
\mathbf{2 9 7 - 5 9 0} \boldsymbol{\mu m}\end{array}$ \\
\hline F-1 & $16.19 \pm 0.415$ & $6.54 \pm 0.310$ & $8.25 \pm 0.215$ & $4.89 \pm 0.185$ \\
\hline F-2 & $14.77 \pm 2.193$ & $8.15 \pm 0.102$ & $9.22 \pm 0.526$ & $3.78 \pm 0.456$ \\
\hline F-3 & $15.95 \pm 0.826$ & $9.25 \pm 0.427$ & $7.21 \pm 0.264$ & $2.85 \pm 0.156$ \\
\hline F-4 & $19.85 \pm 0.152$ & $11.92 \pm 0.670$ & $6.84 \pm 0.816$ & $3.52 \pm 0.156$ \\
\hline F-5 & $24.01 \pm 0.810$ & $9.15 \pm 0.536$ & $6.23 \pm 0.011$ & $2.05 \pm 0.188$ \\
\hline F-6 & $27.55 \pm 0.311$ & $10.88 \pm 0.115$ & $7.14 \pm 0.483$ & $3.71 \pm 0.882$ \\
\hline F-7 & $20.22 \pm 0.402$ & $9.01 \pm 0.045$ & $5.88 \pm 0.151$ & $2.85 \pm 0.456$ \\
\hline F-8 & $24.25 \pm 0.692$ & $10.25 \pm 0.340$ & $6.10 \pm 0.484$ & $2.93 \pm 0.185$ \\
\hline
\end{tabular}

Values are mean $\pm S D, n=3$.

In this prepared Zidovudine microspheres, with the increase in HPMC percentage the distribution of particle size shifts to the higher sieve size due to increase in the internal viscosity of themedium.

\section{Micrometric properties of the beads}

Zidovudine containing microspheres were in the size range of $0.77 \pm 0.76$ to $0.98 \pm 0.94$. Zidovudine -loading amount, stirring speed, curing time, polymer concentration and cross- linking agent seemed to affect the values of particle size. The results were shown in table No.3.

\section{Flow properties of Beads}

The flow property of the microspheres was checked by using the angle of repose method. Acceptable range of angel of repose was found to be $24-31^{\circ}$. All the formulations angle of repose values were shown in the Table -3 . 
Table - 3: flow property, entrapment efficiency, mean diameter of particle of microspheres

\begin{tabular}{|c|c|c|c|c|}
\hline ORMULATION CODE & ANGLE OF REPOSE & ENTRAPMENT EFFICIENCY & $\begin{array}{c}\text { DRUG } \\
\text { CONTENT }\end{array}$ & $\begin{array}{l}\text { MEAN DIAMETER OF } \\
\text { PARTICLE (mm) }\end{array}$ \\
\hline F1 & $31^{\circ} .20^{\prime} \pm 0.11$ & $82.14 \pm 0.59$ & $11.65 \pm 0.12$ & $0.79 \pm 0.02$ \\
\hline F2 & $28^{\circ} .20^{\prime} \pm 0.17$ & $89.60 \pm 0.16$ & $11.96 \pm 0.58$ & $0.77 \pm 0.12$ \\
\hline F3 & $25 \div .10^{\prime} \pm 0.22$ & $90.19 \pm 0.86$ & $12.01 \pm 0.28$ & $0.97 \pm 0.02$ \\
\hline F4 & $24 \stackrel{\circ}{2} 30^{\prime} \pm 0.25$ & $86.16 \pm 0.15$ & $13.25 \pm 0.35$ & $0.98 \pm 0.08$ \\
\hline F5 & $26 \div .60^{\prime} \pm 0.28$ & $91.61 \pm 0.22$ & $12.22 \pm 0.62$ & $0.86 \pm 0.18$ \\
\hline F6 & $24^{\circ}-30^{\prime} \pm 0.54$ & $94.67 \pm 0.54$ & $13.45 \pm 0.48$ & $0.89 \pm 0.38$ \\
\hline F7 & $24^{\circ} 30^{\prime} \pm 0.21$ & $90.10 \pm 0.34$ & $12.94 \pm 0.25$ & $0.85 \pm 0.65$ \\
\hline F8 & $26^{\circ}-30^{\prime} \pm 0.57$ & $92.23 \pm 0.28$ & $14.22 \pm 0.12$ & $0.93 \pm 0.28$ \\
\hline
\end{tabular}

Values are mean $\pm S D, n=3$.

\section{Drug entrapment efficiency \& Drug content}

The drug content of prepared formulations was found to be in the range of 89.15 - 98.47\%. The drug entrapment efficiency of all the formulations was in the range of 82.1494.67. The results of the each formulation drug entrapment efficiency values were shown in Table No: 03. Drug entrapment efficiency of microspheres values of the different formulations were observed and reported, as increases the concentration of sodium alginate and hydroxyl propyl methyl cellulose automatically drug entrapment efficiency also increases and drug content ranges from 11.65 to $14.22 \mathrm{mg}$ were shown in table-3.

\section{In Vitro Drug Release Studies}

The In-Vitro drug release studies of the different formulations cumulative percentage drug release was observed in the range of 84.63-97.17. The release studies were conducted in triplicate and the results were shown in Table 4 and in Figure-1. The formulations F1, F2 containing $1,2 \%$ sodium alginate respectively showed a release of 96.12, 94.15\% after 10 hours. This shows that more sustained release was observed with the increase in percentage of sodium alginate. The formulations F3, F4 containing $3 \%$ sodium alginate and $0.5,1 \%$ sodium carboxy methyl cellulose showed 88.12, $86.17 \%$ drug release respectively. The formulations F5, F6 containing 3\% sodium alginate and $0.5,1 \%$ hydroxyl propyl methyl cellulose showed a release of $97.17,94.01 \%$ after 10 hours. Finally the formulations F7, F8 containing 3\% sodium alginate and 0.5, $1 \%$ Chitosan showed a release of $97.17,94.01 \%$ after 10 hours.

Table - 4: In-Vitro Dissolution Profile for Formulation F1 TO F8

\begin{tabular}{|c|c|c|c|c|c|c|c|c|}
\hline \multirow{2}{*}{$\begin{array}{c}\text { Time } \\
\text { (hrs) }\end{array}$} & \multicolumn{7}{|c|}{ \% Drug Release } \\
\cline { 2 - 9 } & F1 & F2 & F3 & F4 & F5 & F6 & F7 & F8 \\
\hline 1 & $3.42 \pm 0.04$ & $3.32 \pm 0.122$ & $3.54 \pm 0.06$ & $3.11 \pm 0.09$ & $3.55 \pm 0.02$ & $3.32 \pm 0.012$ & $3.55 \pm 0.13$ & $2.92 \pm 0.15$ \\
\hline 2 & $4.92 \pm 0.12$ & $4.24 \pm 0.02$ & $3.85 \pm 0.16$ & $3.22 \pm 0.05$ & $4.24 \pm 0.05$ & $3.96 \pm 0.021$ & $4.77 \pm 0.09$ & $3.23 \pm 0.05$ \\
\hline 3 & $25.55 \pm 0.08$ & $27.15 \pm 0.78$ & $22.55 \pm 0.08$ & $20.55 \pm 0.22$ & $23.95 \pm 0.07$ & $28.56 \pm 0.04$ & $23.25 \pm 0.12$ & $19.77 \pm 0.06$ \\
\hline 4 & $38.97 \pm 0.12$ & $36.84 \pm 0.12$ & $37.32 \pm 0.07$ & $35.67 \pm 0.12$ & $41.27 \pm 0.12$ & $36.84 \pm 0.18$ & $33.85 \pm 0.22$ & $34.52 \pm 0.20$ \\
\hline 6 & $56.22 \pm 0.17$ & $55.13 \pm 0.06$ & $57.14 \pm 0.09$ & $53.25 \pm 0.21$ & $62.45 \pm 0.10$ & $58.25 \pm 0.11$ & $55.22 \pm 0.11$ & $51.11 \pm 0.17$ \\
\hline 8 & $87.39 \pm 0.23$ & $79.17 \pm 0.46$ & $84.55 \pm 0.12$ & $77.85 \pm 0.05$ & $86.36 \pm 0.15$ & $82.57 \pm 0.18$ & $82.78 \pm 0.15$ & $75.78 \pm 0.02$ \\
\hline 10 & $96.12 \pm 0.51$ & $94.15 \pm 0.08$ & $88.12 \pm 0.115$ & $86.17 \pm 0.01$ & $97.17 \pm 0.15$ & $94.29 \pm 0.01$ & $86.22 \pm 0.18$ & $84.63 \pm 0.12$ \\
\hline
\end{tabular}




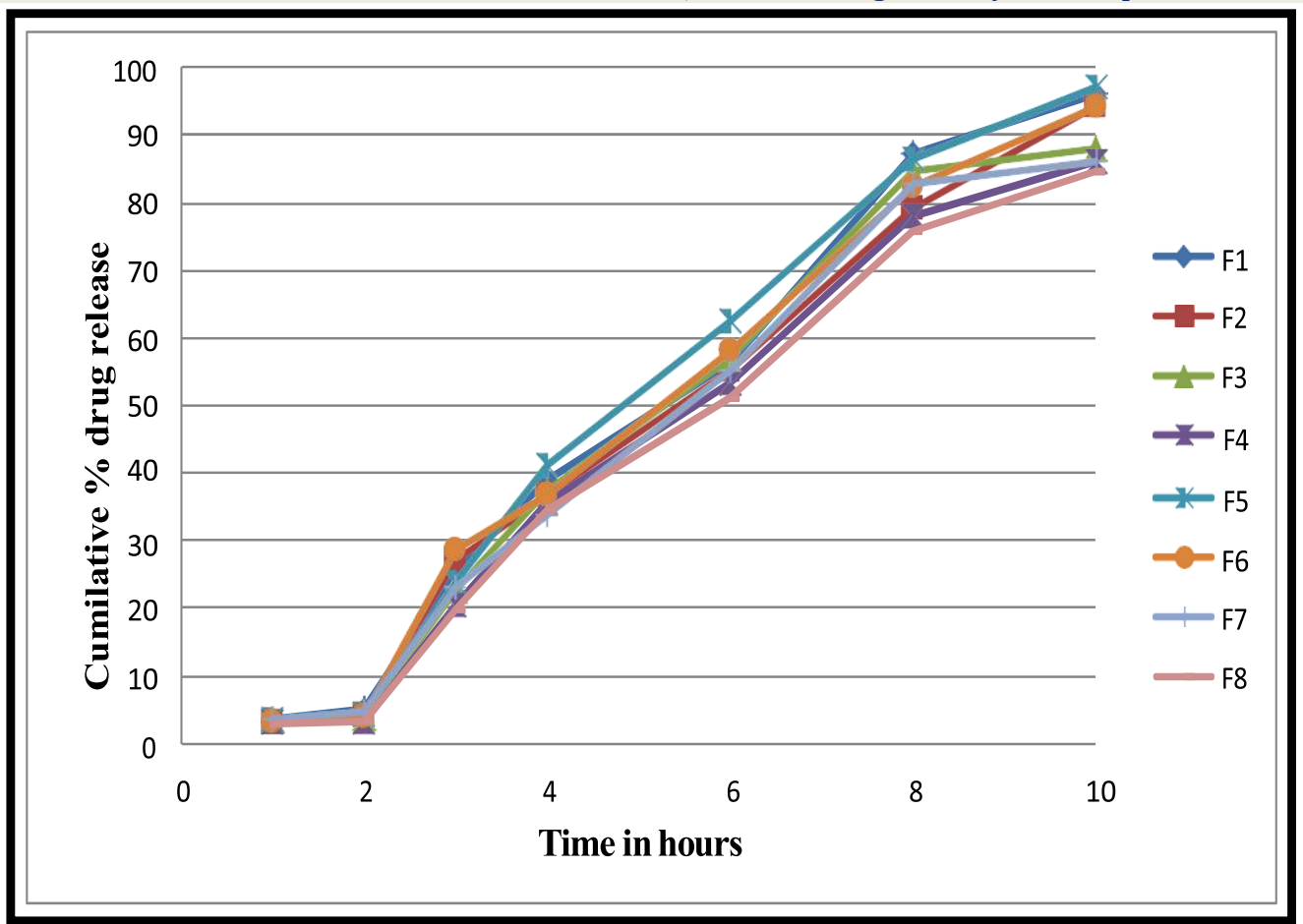

Figure 1: In-Vitro Drug Release of All Eight Formulations

Maximum release of Zidovudine from the various formulations was achieved in 12 hrs or longer, Figure1. Formulation F8 showed sustained drug release, when compared to all other formulations.

\section{Kinetics of drug release}

According to results obtained, the ' $n$ ' value KorsmeyerPeppas equation was in range of 0.910 to 0.905 which suggest the drug release from mixture of polymers and $\mathrm{Na}$ $\mathrm{cmc}$ containing Microspheres were non-fickian diffusion mechanism. Similarly ' $\mathrm{n}$ ' value for hydroxyl propyl methyl cellulose was in range of 0.917 to 0.904 which suggests the drug release was non-fickian diffusion mechanism; similarly ' $n$ ' value for chitosan was in range of 0.935 to 0.912 which suggests the drug release was non-fickian diffusion mechanism super case II transport evidenced with diffusion exponent values $(\mathrm{n})$.

In vitro release data proved that formulation F8 having 1\% Sodium alginate and $1 \%$ chitosan as polymers showed more optimum sustained release profile with maximum entrapment efficiency followed by zero-order kinetics. The release kinetics was shown in Table-5.

The values of diffusion co-efficient ranged between $\mathrm{n}=1.557$ and 1.666 indicating the drug release from the microspheres followed the anomalous transport and super case-II transport mechanism controlled by swelling and relaxation of polymer chains.

Table-5: Drug Release Kinetics Data

\begin{tabular}{|c|c|c|c|c|c|}
\hline \multirow{2}{*}{ Formulation } & \multicolumn{2}{|c|}{$\begin{array}{c}\text { Zero } \\
\text { order }\end{array}$} & \multicolumn{2}{|c|}{ First order } & \multicolumn{2}{|c|}{ Korsermayer-Peppa's } \\
\cline { 2 - 6 } & & $\mathbf{R}$ & $\mathbf{R}$ & $\mathbf{r}$ & $\mathbf{N}$ \\
\hline F1 & 0.978 & 0.781 & 0.934 & 1.599 \\
\hline F2 & 0.984 & 0.867 & 0.915 & 1.603 \\
\hline F3 & 0.967 & & 0.841 & 0.910 & 1.609 \\
\hline F4 & 0.976 & 0.872 & 0.905 & 1.657 \\
\hline F5 & 0.976 & 0.835 & 0.917 & 1.628 \\
\hline F6 & 0.978 & 0.893 & 0.904 & 1.626 \\
\hline F7 & 0.970 & 0.935 & 0.935 & 1.557 \\
\hline F8 & 0.979 & 0.853 & 0.912 & 1.666 \\
\hline
\end{tabular}

\section{Determination of stability of the microspheres}

The stability of microspheres was determined. The samples were then characterized for \% drug content and from the results it can be observed that there was no significant change in the $\%$ drug content of the formulations [22]. The results were summarized in Table- 6 . 
Table- 6: results of assay for formulations F-1 to F-8 after accelerated stability studies.

\begin{tabular}{|c|c|c|c|c|c|c|c|c|}
\hline \multirow{2}{*}{ Days } & \multicolumn{7}{|c|}{ \% Drug Release, 40-c } \\
\cline { 2 - 9 } & F1 & F2 & F3 & F4 & F5 & F6 & F7 & F8 \\
\hline $\mathbf{1}$ & $95.16 \pm 0.01$ & $92.24 \pm 0.10$ & $94.34 \pm 0.08$ & $95.46 \pm 0.12$ & $92.13 \pm 0.81$ & $97.12 \pm 0.15$ & $97.22 \pm 0.12$ & $98.46 \pm 0.05$ \\
\hline $\mathbf{4}$ & $94.50 \pm 0.09$ & $93.23 \pm 0.01$ & $97.16 \pm 0.15$ & $96.14 \pm 0.15$ & $95.12 \pm 0.15$ & $98.52 \pm 0.07$ & $95.16 \pm 0.05$ & $96.14 \pm 0.18$ \\
\hline $\mathbf{1 7}$ & $93.50 \pm 0.10$ & $92.65 \pm 0.12$ & $96.85 \pm 0.88$ & $95.85 \pm 0.47$ & $94.26 \pm 0.45$ & $95.26 \pm 0.07$ & $93.85 \pm 0.08$ & $95.55 \pm 0.14$ \\
\hline $\mathbf{2 1}$ & $93.23 \pm 0.12$ & $92.25 \pm 0.54$ & $96.25 \pm 0.76$ & $95.54 \pm 0.05$ & $93.62 \pm 0.18$ & $94.64 \pm 0.08$ & $93.25 \pm 0.07$ & $95.14 \pm 0.18$ \\
\hline $\mathbf{3 8}$ & $92.89 \pm 0.01$ & $91.73 \pm 0.18$ & $95.75 \pm 0.07$ & $93.57 \pm 0.18$ & $91.28 \pm 0.15$ & $93.82 \pm 0.04$ & $92.75 \pm 0.48$ & $93.57 \pm 0.17$ \\
\hline $\mathbf{4 5}$ & $92.54 \pm 0.11$ & $91.25 \pm 0.78$ & $95.21 \pm 0.16$ & $90.15 \pm 0.78$ & $89.52 \pm 0.13$ & $91.82 \pm 0.18$ & $91.21 \pm 0.18$ & $92.15 \pm 0.08$ \\
\hline
\end{tabular}

Values are mean $\pm S D, n=3$.

\section{Scanning electron microscopy}

Morphological details of the specimens were determined by using a scanning electron microscope (SEM). The morphology of the microspheres was shown in Figure 2. Scanning electron microscopy (SEM) results (Figure 2) show that the microspheres were spherical and that the microspheres prepared with Chitosan had a formed smooth surface.

1 (a)

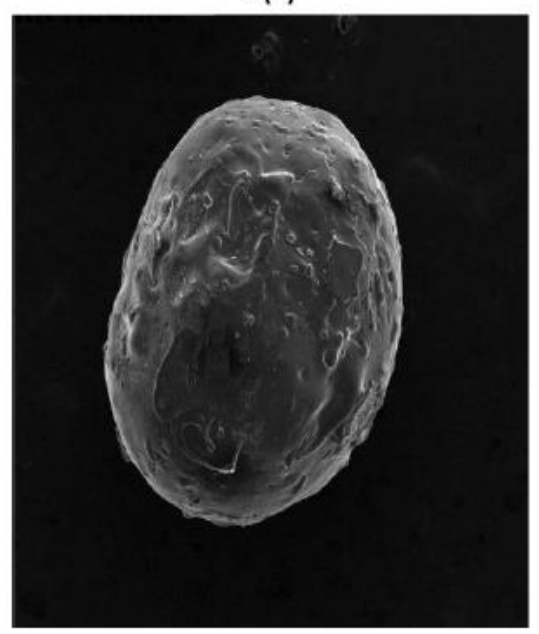

1 (b)

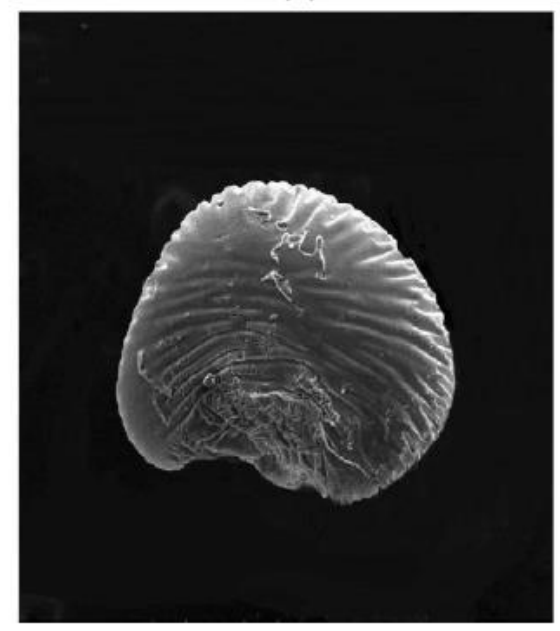

1 (c)

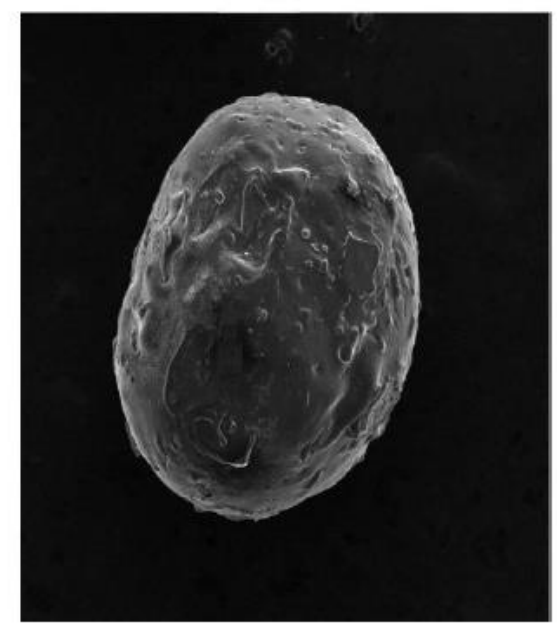

FIGURE 2: SCANNING ELECTRON MICROGRAPHS OF Zidovudine MICROSPHERES 1(a), 1(b), AND 1(c) FORMULATIONS F3, F6, F7

\section{FTIR study}

The FTIR study revealed that the scanning range was $400-4000 \mathrm{~cm}^{-1}$, resolution was $4 \mathrm{~cm}^{-1}$. Spectra of the Zidovudine, and the drug with sodium alginate were obtained and compared for the compatibility. FTIR studies indicates four bands present in the Zidovudine spectrum, namely; $\mathrm{N}-\mathrm{H}, \mathrm{O}-\mathrm{H}, \mathrm{C}=\mathrm{O}, \mathrm{C}=\mathrm{N}$ linkages respectively. The same bands were also found in the spectra of the formulations, showing that no drug-polymer interaction occurred. The figure clearly shows that there was no significant compatibility between the drug and polymer used for the preparations. The FTIR graphs are shown in Figure 3 and 4. 


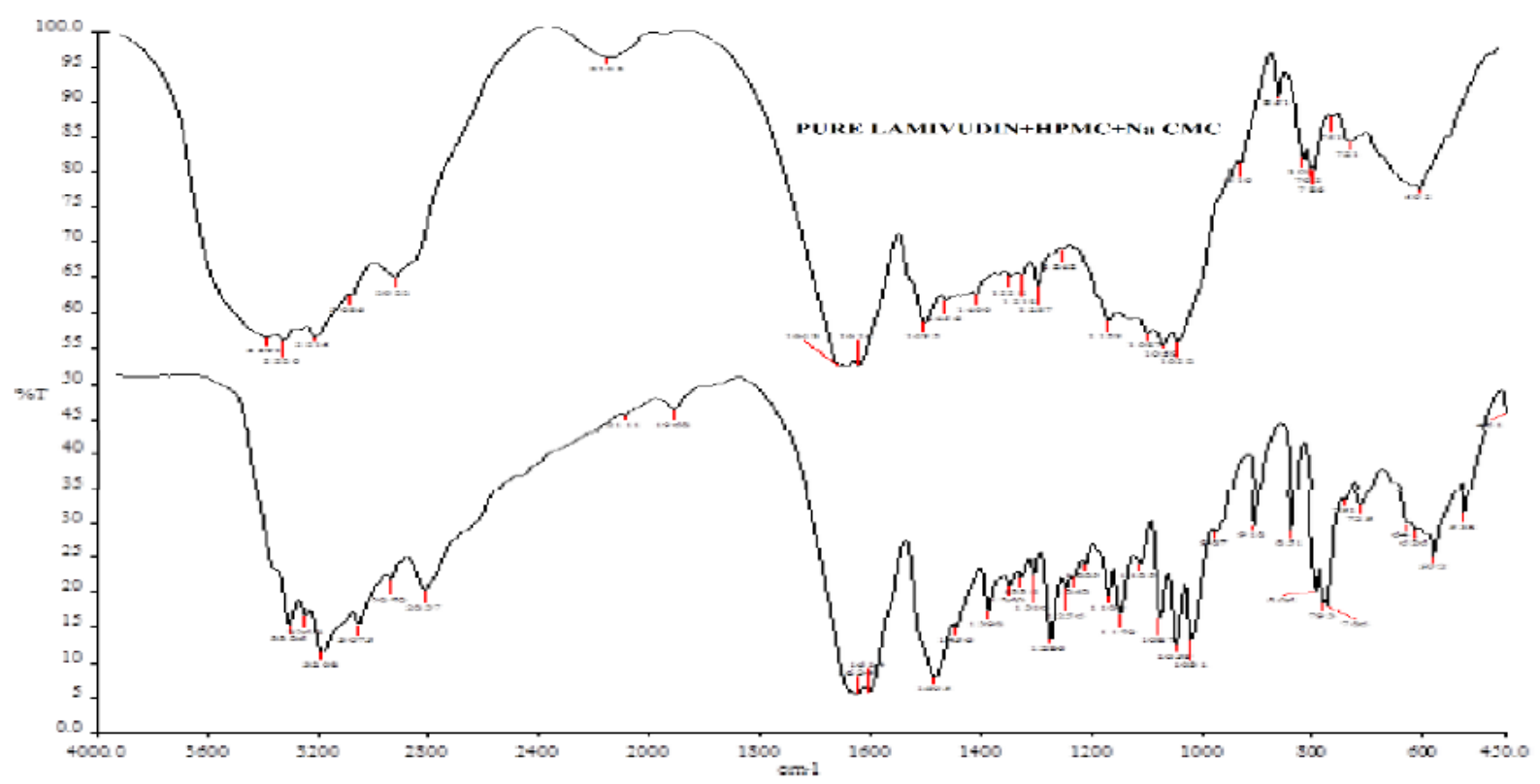

FIGURE 3: FTIR FOR PURE DRUG, SODIUM ALGINATE, HPMC AND NA CMC

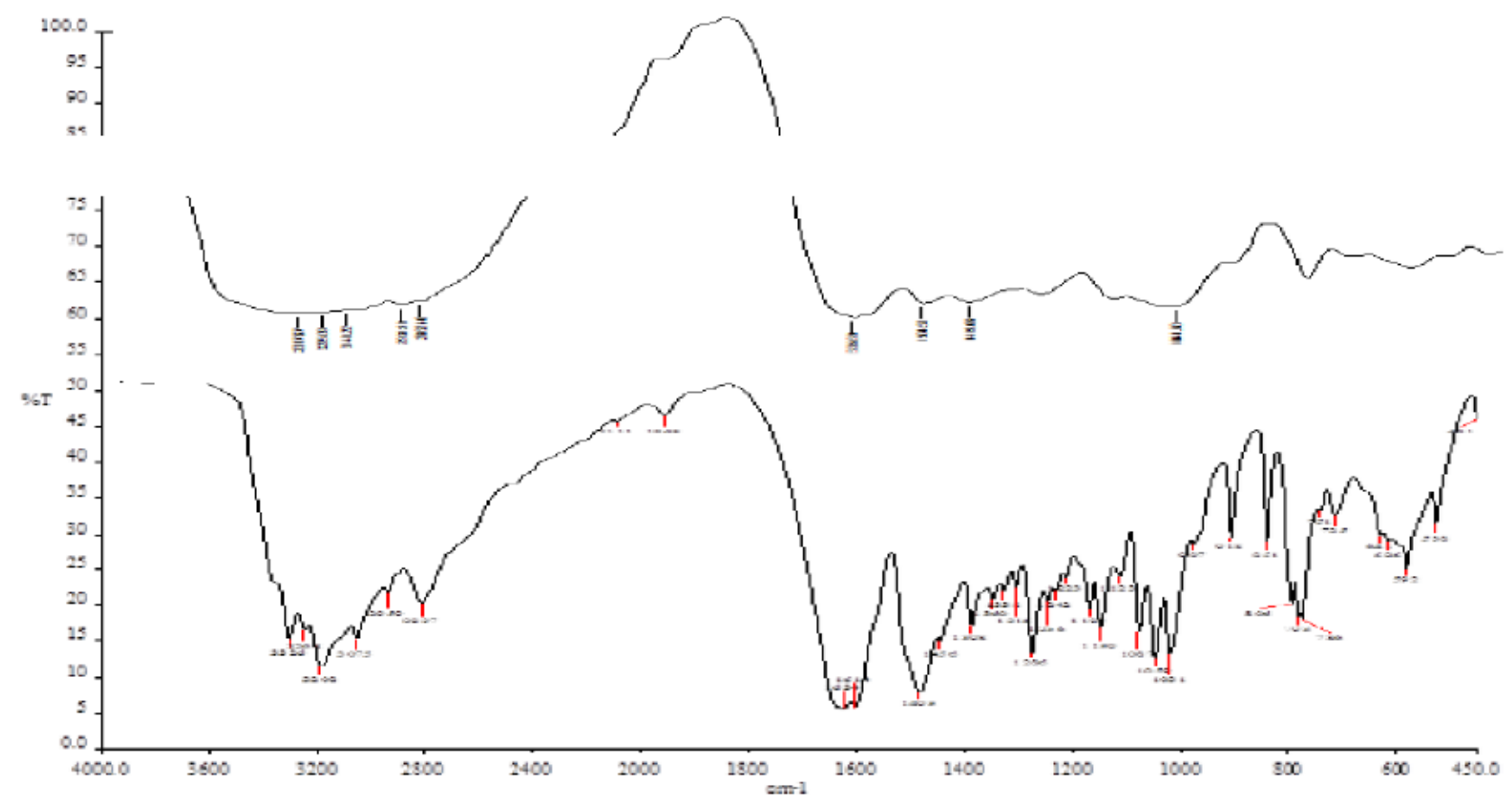

FIGURE 4: FTIR FOR PURE DRUG, SODIUM ALGINATE AND CHITOSAN

\section{CONCLUSION}

In the present study an attempt was made to prepare Zidovudine microspheres by using Ionotropic gelation technique. The method was successfully used for preparation of microspheres using sodium alginate and with other coating polymers like Chitosan, Na CMC, HPMC, as drug release modifiers. The Zidovudine drug release from microspheres formulated with sodium alginate with $1 \%$ Chitosan as coating polymer showed a satisfactory sustained release profile. As the formulation F8 was the best formulation based on better controlled release and good entrapment efficiency. High entrapment efficiency was observed in the microspheres prepared with combination of sodium alginate and Chitosan. The results of accelerated stability study on the microspheres revealed that the formulations were stable. The study further supported with FTIR study for absence of compatibility with drug and polymer. The results proved that the Zidovudine microspheres can be best alternate for conventional tablets for HIV patients' treatment. 


\section{REFERENCES}

[1] Progress Report on the Global Response to the HIV/AIDS Epidemic, 2003.

[2] Over, Peter Heywood, Julian Gold, Indrani Gupta, Subhash Hira, Elliot Marseille, Treatment and Prevention in India Modeling the Cost and Consequences, The International Bank for Reconstruction and Development / The World Bank. 2004, 14.

[3] Manuchair Ebadi, Desk Reference of Clinical Pharmacology, CRC Press, USA, 2008, 2, 378 .

[4] Furman PA, Fyfe JA, St Clair MH, Weinhold K, Rideout JL, Freeman GA, Lehrman SN, Bolognesi DP, Broder S, Mitsuya H, et al. Phosphorylation of 3'-azido-3'-deoxythymidine and selective interaction of the 5 '-triphosphate with human immunodeficiency virus reverse transcriptase. Proc Natl Acad Sci U S A. 1986 Nov; 83, 21, 8333-8337.

[5] Becher F, Landman R, Mboup S, NdeyeToure Kane C, Canestri A, Liegeois F, Vray M, Prevot M H, Leleu G, Benech H. AIDS 2004, 18, 2, 181-187.

[6] Bhandari, Nilesh Raghavan, Vineeth, Himadri sen, Surva Kumar J, inventors. Long acting composition containing zidovudine and Zidovudine. US patent publication US 20050175694 A1. August 11, 2005.

[7] K Prakash P N Raju, K K Shanta and M N Lakshmi, TropJ Pharmaceut Res 2007, 6, 841-847.

[8] Shilpa A, Agrawal SS Ray AR, Controlled Delivery of Drugs from Alginate Matrix, Journal of Macromolecular science Part
C-Polymer reviews. 2003, 43, 187.

[9] Sahoo SK, Dalai SR, Pani NR, Barik BB, Indian drugs.2007, 44, 843-847.

[10] M.C. Gohel., R.K. Parik, A.F. Amin and A.K. Surati. Indian J. Pharm. Sci. 2005, 67,575-581.

[11] Narasimha Rao R, Prakash.K, IJPT, 2011, 3, 1397-1410

[12] Khan GM. The Sciences. 2001, 1,5, 350-354.

[13] Morkhade DM, Fulzele SV, Stturwar PM and Joshi SB. Ind. J. Pharm. Sci. 2006, 68, 53-58.

[14] Higuchi T. J. Pharm. Sci. 1963, 52, 1145-1149.

[15] Peppas NA and Sahlin JJ. Int. J. Pharm. 1989, 57, 169-172.

[16] Manna A, Ghosh I, Goswami N, Ghosh L.K and Gupta B.K., J.Sci.Ind.Res. 1999, 58, 717 -722.

[17] Martin Alfred, Physical Pharmacy, B.I. waverly Pvt Ltd, New Delhi, 1995, 4, 330 - 337, 423 -430.

[18] Lim-L.Y and Wan-LS, Drug Dev. Ind. Pharm, 1997, 23, 973 980.

[19] Patil VB, and Varsha B, Indian J.Pharm. Sci. 2001, 63, 1, 15 19.

[20] Kakkar AP, Indian. J. Pharm. Sci. 1995, 57, 56-60. 